\title{
The determination of thiocyanate in the blood plasma and holding water of Amphiprion clarkii after exposure to cyanide
}

\author{
J. Alexander Bonanno ${ }^{1,2}$, Nancy E Breen ${ }^{3}$, Michael Tlusty ${ }^{1}$, Lawrence Andrade ${ }^{4}$, Andrew L Rhyne ${ }^{\text {Corresp. } 5}$ \\ ${ }^{1}$ School for the Environment, University of Massachusetts at Boston, Boston, Massachusetts, United States \\ 2 Takara Bio USA, Inc., Mountain View, CA, United States \\ 3 Department of Chemistry, Roger Williams University, Bristol, Rhode Island, United States \\ 4 Dominion Diagnostics, North Kingstown, Rhode Island, United States \\ 5 Department of Biology, Marine Biology, and Environmental Science, Roger Williams University, Bristol, Rhode Island, United States \\ Corresponding Author: Andrew L Rhyne \\ Email address: arhyne@rwu.edu
}

The illegal practice of cyanide fishing continues throughout the Indo-Pacific. To combat this destructive fishing method, a reliable test to detect whether a fish has been captured using cyanide ( $\mathrm{CN}$ ) is needed. We report on the toxicokinetics of acute, pulsed $\mathrm{CN}$ exposure and chronic thiocyanate (SCN) exposure, the major metabolite of $\mathrm{CN}$, in the clownfish species, Amphiprion clarkii. Fish were pulse exposed to $50 \mathrm{ppm} \mathrm{CN}$ for 20 or $45 \mathrm{~s}$ or chronically exposed to 100 ppm SCN for 12 days and blood plasma levels of SCN were measured. SCN blood plasma levels reached a maximum concentration (301- 468 ppb) 0.13 - 0.17 days after exposure to $\mathrm{CN}$ and had a 0.1 to 1.2 day half-life. The half-life of blood plasma SCN after chronic exposure to SCN was found to be 0.13 days. Interestingly, we observed that when a fish, with no previous CN or SCN exposure, was placed in holding water spiked to $20 \mathrm{ppb} \mathrm{SCN}$, there was a steady decrease in the SCN concentration in the holding water until it could no longer be detected at $24 \mathrm{hrs}$. Under chronic exposure conditions (100 ppm,12 days), trace levels of SCN ( 40 ppb) were detected in the holding water during depuration but decreased to below detection within the first $24 \mathrm{hrs}$. Our holding water experiments demonstrate that low levels of SCN in the holding water of $A$. clarkii will not persist, but rather will quickly and steadily decrease to below detection limits refuting several publications. After $\mathrm{CN}$ exposure, $A$. clarkii exhibits a classic two compartment model where $\mathrm{SCN}$ is eliminated from the blood plasma and is likely distributed throughout the tissue. Similar studies of other species must be examined to continue to develop our understanding of $\mathrm{CN}$ metabolism in marine fish before a reliable cyanide detection test can be developed. 


\section{The determination of thiocyanate in the blood plasma and holding \\ 2 water of Amphiprion clarkii after exposure to cyanide.}

3

4 J. Alexander Bonanno ${ }^{1 \dagger}$, Nancy E. Breen ${ }^{2}$, Michael F. Tlusty ${ }^{1}$, Lawrence J. Andrade ${ }^{3}$ and 5 Andrew L. Rhyne 4

6

$7 \quad{ }^{1}$ School for the Environment, University of Massachusetts at Boston, Boston, MA, USA

8 †Current Affiliation: Takara Bio USA, Inc., Mountain View, CA 94043, USA

$9{ }^{2}$ Department of Chemistry, Roger Williams University, Bristol, RI, USA

$10{ }^{3}$ Dominion Diagnostics, North Kingstown, RI, USA

$11{ }^{4}$ Department of Biology, Marine Biology, and Environmental Science, Roger Williams

12 University, Bristol, RI, USA

14 Corresponding Author:

15 Andrew L. Rhyne

16 Department of Biology, Marine Biology, and Environmental Science

17 One Old Ferry Road

18 Bristol, RI 02809

19 Email address: arhyne@rwu.edu 


\section{ABSTRACT}

23 The illegal practice of cyanide fishing continues throughout the Indo-Pacific. To combat this

24 destructive fishing method, a reliable test to detect whether a fish has been captured using

25 cyanide $(\mathrm{CN})$ is needed. We report on the toxicokinetics of acute, pulsed $\mathrm{CN}$ exposure and

26 chronic thiocyanate ( $\mathrm{SCN}$ ) exposure, the major metabolite of $\mathrm{CN}$, in the clownfish species,

27 Amphiprion clarkii. Fish were pulse exposed to $50 \mathrm{ppm} \mathrm{CN}$ for 20 or $45 \mathrm{~s}$ or chronically exposed

28 to 100 ppm SCN for 12 days and blood plasma levels of SCN were measured. SCN blood plasma

29 levels reached a maximum concentration $(301-468 \mathrm{ppb}) 0.13-0.17$ days after exposure to $\mathrm{CN}$

30 and had a 0.1 to 1.2 day half-life. The half-life of blood plasma SCN after chronic exposure to

31 SCN was found to be 0.13 days. Interestingly, we observed that when a fish, with no previous

$32 \mathrm{CN}$ or SCN exposure, was placed in holding water spiked to $20 \mathrm{ppb} \mathrm{SCN}$, there was a steady

33 decrease in the SCN concentration in the holding water until it could no longer be detected at 24

34 hrs. Under chronic exposure conditions (100 ppm,12 days), trace levels of SCN ( 40 ppb) were

35 detected in the holding water during depuration but decreased to below detection within the first

$3624 \mathrm{hrs}$. Our holding water experiments demonstrate that low levels of SCN in the holding water

37 of $A$. clarkii will not persist, but rather will quickly and steadily decrease to below detection

38 limits refuting several publications. After $\mathrm{CN}$ exposure, A. clarkii exhibits a classic two

39 compartment model where $\mathrm{SCN}$ is eliminated from the blood plasma and is likely distributed

40 throughout the tissue. Similar studies of other species must be examined to continue to develop

41 our understanding of CN metabolism in marine fish before a reliable cyanide detection test can

42 be developed. 
45

46 Coral reef ecosystems boast the greatest diversity of marine life globally (Bruno \& Selig 2007;

47 Reaka-Kudla 1997) making them one of the most valuable ecosystems on our planet, yet they are 48 also one of the most threatened (Descombes et al. 2015; Hughes et al. 2017). They are being 49 50

\section{INTRODUCTION} stressed to their tipping point largely by climate change, but other anthropogenic activities are playing a role in their destruction including illegal fishing practices (Burke et al. 2012; Dietzel et al. 2020; Hoegh-Guldberg 1999; Hughes et al. 2017).

One widely used illegal fishing practice in the Indo-Pacific that threatens coral reefs is the use of cyanide $(\mathrm{CN})$ to capture reef fish. Cyanide has been used as a stunning agent to collect fish for over 60 years (Bellwood 1981; Frey 2013; Lewis \& Tarrant Jr 1960; Rubec et al. 2003). This practice is most often used for the marine aquarium trade (MAT) and the live reef food fish trade (LRFT) primarily in the Indo-Pacific region where $75 \%$ of all coral reefs are located (Barber \& Pratt 1997; Bruno \& Selig 2007; Davis et al. 2017; Graham 2001; Losada \& Bersuder 2017; Rubec 1986). Cyanide fishing most often involves dissolving tablets of potassium or sodium cyanide in a squirt bottle filled with seawater. Fisherfolk then squirt the concentrated CN solution onto the fish that inhabit the reef and in crevices in the reef where the fish hide. At sublethal doses, which vary depending on the size and species of the fish, $\mathrm{CN}$ temporarily paralyzes the fish, immobilizing them for easy capture. Despite being illegal, this fishing practice continues to be used throughout the region. Fisherfolk rely on the middlemen to provide cyanide, food, boats, and minimal pay in return for high volumes of fish caught with cyanide (Rubec et al. 2001). Policing against this fishing method is difficult, as there is no easy and definitive way to test if a fish has been captured using $\mathrm{CN}$. As a result, enforcement of $\mathrm{CN}$ fishing laws is challenging, if not impossible (Losada \& Bersuder, 2017).

The squirt bottle method of $\mathrm{CN}$ delivery makes it difficult for collectors to control the amount of solution dispensed, resulting in widely variable doses received. As $\mathrm{CN}$ is nonselective, and dosing is not precise, this method often kills both the targeted species and non-targeted species in the squirt zone (Frey 2013). Even when fish survive the exposure, there are reports of increased fish mortality post-capture associated with this fishing practice (Cervino et al. 2003; Davis et al. 2017; Hall \& Bellwood 1995; Pyle 1993; Rubec 1986; Rubec et al. 2003). Furthermore, stony corals, which are an important structural component of coral reef ecosystems, are often damaged 
75 from exposure to $\mathrm{CN}$ during the fishing process (Cervino et al. 2003; Jones \& Hoegh-Guldberg 76 1999). Once the fish are stunned, fisherfolk also may break stony corals to gain access to the 77 fish, increasing the long-term damage to reefs (Bruckner \& Roberts 2008).

78 Attempts to curtail the use of $\mathrm{CN}$ as a capture method via post-capture testing have not been 79 successful (Dalabajan 2005; Erdmann 1999). The Cyanide Detection Test (CDT), which uses a

80 $\mathrm{CN}$ ion-selective electrode to measure $\mathrm{CN}$ found in tissues of fish, was developed by the International Marinelife Alliance (IMA) and the Philippines Bureau of Fisheries and Aquatic Resources (BFAR) and was used in the Philippines in the 1990s (Barber \& Pratt 1997; Manipula et al. 2001). The CDT test was developed by spiking samples of fish homogenate with CN, rather than systematically exposing marine fish to cyanide and testing the exposed fish. There is no reported validation of this test for $\mathrm{CN}$ on live fish with known $\mathrm{CN}$ exposure. It was suggested that the test was unreliable as an indicator of $\mathrm{CN}$ exposure primarily due to interferences resulting in false positives (Balboa 2017; Mak et al. 2005). Bruckner \& Roberts (2008) thoroughly documented the shortcomings of the IMA CDT. The test required lethal sampling, was time-consuming, labor-intensive, and was never properly field-tested and verified. Mak et al. (2005) attempted to validate the IMA CDT on fish exposed to CN in their laboratory. They exposed fish to enough $\mathrm{CN}$ to induce mortality, but found that $\mathrm{CN}$ was not detected in the homogenates of the exposed fish using the CDT methodology (Mak et al. 2005). Other CN detection methods have been proposed (Mak et al. 2005), but the presumed rapid detoxification of $\mathrm{CN}$ is the major difficulty in detecting $\mathrm{CN}$ exposure. If marine fish have a similar detoxification pathway to mammals, and it is believed they do because of the presence of the enzyme rhodanese, any test for $\mathrm{CN}$ caught fish must be administered very soon after exposure, likely within hours (Day et al. 2018; Logue et al. 2010).

As an alternative to detecting $\mathrm{CN}$ directly, thiocyanate ( $\mathrm{SCN}$ ), a metabolite of $\mathrm{CN}$ exposure, is often used as an indicator of CN exposure (Breen et al. 2019; Day et al. 2018; Youso et al. 2012). In mammals, the CN detoxification pathway is well established. Two sulfur-transferases, rhodanese, and 3-mercaptopyruvate sulfurtransferase are responsible for catalyzing the formation of SCN from CN by sulfuration (Day et al. 2018), and SCN is eliminated in urine by the kidneys. In marine fish, the method of elimination has not yet been determined, but Vaz et al. (2012) and Rubec et al. (2003) speculated a similar pathway to mammals because of the presence of the 
105 rhodanase enzyme. In a now refuted study, Vaz et al. (2012) claimed that SCN excreted in the

106 urine of the marine fish Amphiprion clarkii exposed to CN could be detected in their holding

107 water for at least 28 days. The same group used this technique to monitor the MAT in the EU for

108 the presence of cyanide fishing in the exporting countries (Vaz et al. 2017). The hope was that

109 this technique could serve as a test for $\mathrm{CN}$ exposure in marine fish, but in the nine years that

110 have passed since it was first reported, it has never been replicated by any other lab even though

111 multiple laboratories have attempted to do so (Breen et al. 2018; Herz et al. 2016; reviewed by

112 Murray et al. 2020). Breen et al. (2018) demonstrated by using a mass balance calculation that

113 the SCN concentrations reported by Vaz et al. (2012) and the concomitant doses of CN that the

114 fish would have had to receive given those SCN concentrations were an order of magnitude

115 higher than all known LD50s for CN in vertebrate species. If marine fish excrete SCN after

116 exposure to $\mathrm{CN}$, then the concentration of $\mathrm{SCN}$ in the holding water must be well below current

117 detection limits.

118 The next logical step in developing our understanding of cyanide detoxification in marine fish is

119 to look for SCN or CN directly in bodily fluids of marine fish exposed to CN. This will provide

120 much needed information on cyanide toxicokinetics in marine fish and thus eliminate the need

121 for speculation and uncertainty when applying mammalian models to marine fish. Indeed,

122 elevated levels of SCN in the blood plasma of marine fish after acute pulsed exposure to CN

123 have been recently reported (Breen et al. 2019). SCN concentrations in the blood plasma of the

124 laboratory cultured marine fish Amphiprion ocellaris were observed to be above control levels

125 up to 41 days post-exposure to $\mathrm{CN}$, which was the longest time sampled. This study reported

126 both a fast and a slow half life corresponding to an initial fast elimination of SCN in blood

127 plasma followed by a much slower elimination from the blood plasma as evidenced by long

128 residence times of low levels of SCN above that found in the controls. Breen et al. (2019)

129 speculated that the observation of both a fast and slow elimination rate of SCN from the blood

130 plasma might be due to multiple elimination pathways in marine fish. These rates could also be

131 governed by the availability of sulfur donors and the rate of diffusion from organs and tissues

132 with limited blood flow (Day et al. 2018).

133 Breen et al. (2019) were the first to report the half-life of SCN in the blood plasma of a marine

134 fish following $\mathrm{CN}$ exposure. The report was for a single species from an aquaculture stock with 
135 limited genetic diversity within the replicate fish. Over 2,300 documented reef fish taxa of

136 various sizes are traded in the MAT (Rhyne et al. 2012; Rhyne et al. 2017) and while the $A$.

137 ocellaris work was a vital first step in understanding the fate of $\mathrm{CN}$ in marine fish, the species

138 and size dependent variation of $\mathrm{CN}$ metabolism is not known. This work must be extended to

139 other species and the endogenous levels of SCN in marine fish in the wild must also be known

140 before any test that relies on $\mathrm{SCN}$ as a marker for $\mathrm{CN}$ exposure can be considered for widespread

141 use.

142 In following up our work on Amphiprion ocellaris (Breen et al. 2019), this study examines

143 toxicokinetics a congeneric clownfish species (A. clarkii), the same species used by Vaz et al.

144 (2012). In an acute exposure study, $A$. clarkii were pulse exposed to $\mathrm{CN}$ and the rate of

145 elimination of SCN from the blood plasma following exposure was determined by ultra high-

146 performance liquid chromatography (UHPLC) with mass spectrometry (MS). In a chronic

147 exposure study, $A$. clarkii were exposed to SCN and the rate of elimination of SCN from the

148 blood plasma was determined using high performance liquid chromatography (HPLC) with UV

149 absorbance detection. For both exposures, the toxicokinetics of SCN elimination is reported. The

150 holding water containing the $A$. clarkii that were chronically exposed to SCN was tested for the

151 presence of SCN during depuration. With chronic, high-level exposure, the possibility of

152 detection of SCN in holding water during depuration via bodily fluid excretion is drastically

153 enhanced.

155 METHODS

156 Test species

157 Experiments were approved by the Roger Williams University Institutional Animal Use and Care

158 Committee (Approval \#R180820). A. clarkii of approximately 6-12 months of age were cultured

159 in captivity at Roger Williams University or Sea \& Reef Aquaculture, Franklin, ME, thereby

160 ensuring they were not collected with or previously exposed to CN (Table 1). For all

161 experiments, the temperature of the water holding the fish was maintained to $25^{\circ} \mathrm{C}$ by placing

162 the holding tank containing the fish in either a temperature-controlled room or in a warm water

163 bath. All fish were fed pelletized food (Skretting Green Granule $1 \mathrm{~mm}$ ) once per day unless

Peer] reviewing PDF | (2020:04:48457:2:0:NEW 3 Oct 2021) 
164 otherwise noted. Water quality was maintained through daily water changes (100\%) at a salinity 165 of 30 with light aeration. Natural seawater was used to house fish throughout each experiment.

166 All seawater was mechanically filtered down to one micron, chlorinated, and then dechlorinated

167 with UV sterilization and carbon filtration and routinely tested for the presence of SCN.

\section{CN and SCN Exposures}

169 During the acute $\mathrm{CN}$ treatments, fish were pulse exposed to a solution of $50 \mathrm{ppm} \mathrm{CN}(\mathrm{NaCN}$, 170 MilliporeSigma, St Louis, MO, USA 380970) for $20 \mathrm{~s}$ and $45 \mathrm{~s}$ in the first trial and $45 \mathrm{~s}$ in the 171 second trial (Table 1). Groups of fish were placed in baskets and immersed in the CN solution

172 for the pre-determined time. The fish were then rinsed by transferring the basket containing the

173 fish to two successive seawater baths from the same source and at a salinity of 30 . After rinsing,

174 fish were housed by their exposure group in round, $20 \mathrm{~L}$ polycarbonate tanks containing

175 seawater with light aeration. The first $\mathrm{CN}$ exposure trial examined the SCN concentration in

176 blood plasma of 4 - 7 fish for each sampling point during the first 13 days post-exposure.

177 Collection times were approximately 1, 3, 6, 8 and $15 \mathrm{hrs}$ and 1, 2, 3, 7, 12, and 13 days post-

178 exposure. For the second $\mathrm{CN}$ exposure trial, the SCN concentration in the blood plasma of 4-8

179 exposed fish was monitored until two months post-exposure. Collection times were $4 \mathrm{hrs}, 12 \mathrm{hrs,}$

$1802,7,18,50$, and 72 days post-exposure. Blood plasma was also collected from a total of 21

181 control fish not exposed to $\mathrm{CN}$ across the two trials.

182 For the SCN treatment, fish were chronically exposed to $100 \mathrm{ppm}$ SCN (NaSCN,

183 MilliporeSigma, St Louis, MO, USA 467871) for 12 days (Table 1). Fish were housed in three

184 round, 20 L polycarbonate tanks holding $15 \mathrm{~L}$ of seawater with 12 - 13 fish in each tank. Fish 185 were fed daily and complete water changes were performed after each feeding. After 12 days, 186 each fish was rinsed thoroughly by submersing it in three consecutive seawater baths to remove 187 all SCN from the surface of the fish. After rinsing, the fish were housed together with their 188 respective exposure groups in three separate $20 \mathrm{~L}$ polycarbonate tanks for depuration. During 189 depuration, the tanks and fish were maintained as above. Once depuration was initiated, 4 - 9 fish 190 were sampled at 1, 2, 4, 8, and 16, hrs and 1, 3 and 16 days. While depurating, the holding water 191 of the fish was also sampled over the first 72 hrs to test for the presence of excreted SCN. Four 192 control fish were also sampled at the end of the depuration period.

\section{SCN in Holding Water}


194 A second SCN chronic exposure trial was carried out on A. clarkii with an even more thorough

195 rinsing procedure. Fish $(\mathrm{n}=10)$ were exposed to $100 \mathrm{ppm} \mathrm{SCN}$ for 12 days in a $20 \mathrm{~L}$

196 polycarbonate tank as described above. To begin the depuration period, individual fish were

197 rinsed by submersion in three different seawater baths (4 L) and placed in covered beakers

198 containing $500 \mathrm{~mL}$ of seawater, one fish per beaker. The rinse water was changed after each fish

199 was rinsed. To monitor for the possibility of cross contamination, an additional 6 beakers were

200 held in the same area, 3 containing non-exposed fish, and 3 with just seawater, no fish. Water

201 samples $(1 \mathrm{~mL})$ were collected from each beaker before the addition of any fish, and then

202 immediately after the addition of the fish. Following this, samples were collected at 2, 4, 8, 12,

203 24, 36, 48 and 72 hrs. Water changes were performed every 24 hrs. Sampling at 24, 36, 48 and

20472 hrs was carried out just prior to the water change. Fish were fed during exposure but not

205 during depuration. The SCN blood plasma levels of half the fish were measured at 48 hrs and the

206 SCN blood plasma levels for the fish remaining were measured after the final sampling at $72 \mathrm{hrs}$

207 when the study was concluded. SCN blood plasma was measured as described below.

208 An additional holding water experiment was undertaken to further examine the previous results.

209 Here, fish $(\mathrm{n}=10)$ with no known previous exposure to SCN, were placed in individual $500 \mathrm{~mL}$

210 beakers of seawater spiked to $20 \mathrm{ppb}$ with SCN. Water samples were collected before spiking the

211 water, after spiking the water with $\operatorname{SCN}(\mathrm{t}=0)$, and at 2, 4, 8, and $16 \mathrm{hrs}$. At $24 \mathrm{hrs}$ the water was

212 sampled, changed, spiked back to $20 \mathrm{ppb}$, and re-sampled. After a second $24 \mathrm{hr}$ interval (48 hrs

213 total), the water was sampled. The SCN blood plasma levels of half the fish were measured at 24

214 hrs (before water change and re-spike). The SCN blood plasma levels for the fish remaining were

215 measured after the final sampling at $48 \mathrm{hrs}$ when the study was concluded. SCN blood plasma

216 was measured as described below. In both experiments holding water samples were collected

217 before adding fish or SCN to test the water for the presence of SCN.

\section{Blood Plasma Collection}

219 Blood plasma was collected for SCN analysis following the method described by Breen et al.

220 (2019). The exact dates and times are noted in supplemental material. Fish were heavily

221 anesthetized with tricaine methanesulfonate (Western Chemical Inc., Ferndale, WA, USA) at a

222 concentration of $200 \mathrm{ppm}$, buffered 2:1 with sodium bicarbonate in saltwater, and then dried and

223 weighed on an analytical balance. Blood was collected by severing of the caudal peduncle with a 
224 \#21 surgical blade. For fish weighing less than $4 \mathrm{~g}$, blood was collected in $40 \mathrm{~mm}$ heparinized 225 microhematocrit tubes (Jorvet, Loveland, CO, USA) while for fish weighing greater than $4 \mathrm{~g}$, 226 blood was collected in $125 \mu \mathrm{L}$ heparinized microcapillary blood collection tubes (RAM

227 Scientific, Nashville, TN, USA). Following blood collection, fish were euthanized via pithing.

228 The $40 \mathrm{~mm}$ heparinized microhematocrit tubes were then centrifuged (ZipCombo Centrifuge,

229 LW Scientific, Lawrenceville, GA, USA) at room temperature at 3,000 rpm (470 g) for two min

230 followed by 6,000 rpm (1900 g) for five min to separate the red blood cells from the blood

231 plasma. The tubes were then snapped at the plasma and red blood cell interface and the blood

232 plasma was aspirated from the capillary tubes into pre-weighed $1.7 \mathrm{~mL}$ centrifuge tubes and then

233 re-weighed to determine the mass of blood plasma collected. The $125 \mu \mathrm{L}$ micro-capillary blood

234 collection tubes were spun at 12,000 rpm (6900 g) for $12 \mathrm{~min}$ at room temperature. The top

235 blood plasma layer was then pipetted into a pre-weighed $1.7 \mathrm{~mL}$ centrifuge tube. The centrifuge

236 tubes containing the blood plasma were then reweighed to determine the blood plasma mass.

237 Blood plasma was stored in these centrifuge tubes at $-80^{\circ} \mathrm{C}$ until analyzed.

238 Thiocyanate analysis

239 Before blood plasma analysis, proteins were precipitated with cold HPLC grade acetonitrile

240 (MilliporeSigma, St Louis, MO, USA) (Blanchard 1981). Acetonitrile was added in the ratio of

$241 \quad 1: 5(\mathrm{v} / \mathrm{v})$ and the solution was vortexed for $20 \mathrm{~s}$ and then centrifuged at 12,000 rpm $(6900 \mathrm{~g})$ for

$24210 \mathrm{~min}$ at room temperature. The supernatant was transferred to a new $1.7 \mathrm{~mL}$ centrifuge tube

243 and the acetonitrile was evaporated with nitrogen gas in an Zymark TurboVap LV Evaporator

244 (Zymark, Hopkinton, MA, USA) at $70^{\circ} \mathrm{C}$. The residue was reconstituted in enough HPLC grade

245 water (MilliporeSigma, St Louis, MO, USA) to make a 1:5 or 1:10 dilution of the plasma

246 collected and vortexed for $20 \mathrm{~s}$.

247 For the first chronic exposure to $100 \mathrm{ppm}$ SCN experiment, the SCN in the blood plasma was

248 analyzed using the HPLC-UV method described by (Breen et al. 2019; Breen et al. 2018)

249 originally adopted from Rong et al. (2005). For the SCN blood plasma half-life experiments

250 following $\mathrm{CN}$ exposure, the second SCN chronic exposure experiment (with holding water

251 sampling), and the subsequent holding water experiments, SCN concentrations were analyzed

252 following the method developed by Bhandari et al. (2014) and modified for seawater by Breen et

253 al. (2018). In this method, SCN is chemically modified with monobromobimane (MBB) to form 
254 a SCN-bimane product. The prepared blood plasma $(50 \mu \mathrm{L})$ was added to a $1.7 \mathrm{~mL}$

255 microcentrifuge tube. A working solution of the internal standard $\left(200 \mathrm{ppb} \mathrm{NaS}^{13} \mathrm{C}^{15} \mathrm{~N}\right)$

256 (Cambridge Isotope Labs) and MBB (Monobromobimane, Cayman Chemical 17097), $4 \mathrm{mM}$ in

257 borate buffer $(0.1 \mathrm{M}, \mathrm{pH}=8)$, was prepared in a 2.5:1 ratio just prior to addition to the blood

258 plasma. Then, this solution $(35 \mu \mathrm{L})$ was added to each sample. The resulting solution was heated

259 to $70^{\circ} \mathrm{C}$ for $15 \mathrm{~min}$ to form the bimane-SCN complex. Standard solutions of SCN (5.0 ppb-

$26025.0 \mathrm{ppm}$ ) were prepared in both HPLC grade water and in commercially available salmon blood

261 plasma (MyBioSource inc., San Diego, CA, USA) and were derivatized in the same manner as

262 the samples. As described in Breen et al. (2019), five-point calibration curves were run using

263 standards in HPLC grade water prepared with MBB in the same manner as the samples just prior

264 to all blood plasma analysis, such that the concentration of standards bracketed the expected

265 blood plasma concentration.

266 The derivatized samples were analyzed using a UHPLC and column conditions described in

267 Muñoz-Muñoz et al. (2017) which comprised an Acquity UPLC ${ }^{\circledR}$ I-Class (Waters Corp.,

268 Milford, MA) and Q-Exactive ${ }^{\mathrm{TM}}$ hybrid Quadrupole-Orbitrap ${ }^{\mathrm{TM}}$ high-resolution accurate mass

269 (HRAM) mass spectrometer (Thermo Fisher Scientific, Waltham, MA). A Kinetex 1.7 $\mu$ m XB-

$270 \mathrm{C} 18100 \AA 2.1 \times 50 \mathrm{~mm}$ column held at $40^{\circ} \mathrm{C}$ was used for the gradient chromatographic

271 separation (Phenomenex, Torrance, CA) with $10 \mathrm{mM}$ ammonium formate as mobile phase A and

$27210 \mathrm{mM}$ ammonium formate in methanol as mobile phase B. The flow rate was $0.25 \mathrm{~mL} / \mathrm{min}$, and

273 gradient conditions were as follows: 10-100\% B (0.00-3.00 $\mathrm{min}), 100 \% \mathrm{~B}(3.00-4.00 \mathrm{~min})$,

274 followed by $2.00 \mathrm{~min}$ of re-equilibration time at initial conditions (total chromatographic run

275 time $7.00 \mathrm{~min}$ ). The Q-Exactive source conditions in electrospray ionization negative mode were

276 as follows: sheath gas flow rate 55, auxiliary gas flow rate 15, sweep gas flow rate 2, spray

277 voltage $4.50 \mathrm{kV}$, capillary temperature $300^{\circ} \mathrm{C}$, s-lens rf level 55, auxiliary gas heater

278 temperature $500^{\circ} \mathrm{C}$. Tracefinder ${ }^{\mathrm{TM}} 3.2$ (Thermo Fisher Scientific, Waltham, MA) was used for

279 data acquisition and processing. Thermo Xcalibur ${ }^{\mathrm{TM}} 3.0$ (Thermo Fisher Scientific, Waltham,

280 MA) was also used for data processing.

281 The Q-Exactive acquisition method comprised a full-scan of 50-300 $\mathrm{m} / \mathrm{z}$ with a resolving power

282 of 70,000. Analyte identity was established relative to a standard by scoring the following

283 qualitative criteria using TraceFinder 3.2: retention time ( $\mathrm{rt} \pm 0.15 \mathrm{~min})$, full-scan accurate mass 
284 ( \pm 5 ppm window), and full-scan isotope pattern (scores range $0-100$, and a score of $\geq 70$ was

285 used as the positive cutoff). Analyte quantitation was performed using the peak area ratio from

286 the full-scan extracted ion chromatograms (XIC) of the analyte (248.04992) and its internal

287 standard (250.05031); the XIC mass window was the accurate mass \pm 5 ppm in all cases.

288 Analyte validation and quantification followed Breen et al. (2018), validation of peak area ratio

289 (analyte/internal standard) and quantification by a linear weighted ( $1 / \mathrm{x})$ regression of calibration

290 standards. Plasma, water, or seawater calibration standards were prepared fresh for each run - no

291 legacy calibration curves were used. Calibration standards were used only if the calculated

292 concentration deviated $\leq 10 \%$ from the nominal concentration. The analyte response at the lower

293 limits of quantification and detection (LLOQ $=5 \mathrm{ppb}$ and LOD $=2.5 \mathrm{ppb}$ ) had a signal-to-noise

294 ratio $(\mathrm{S} / \mathrm{N}) \geq$ ten and three respectively.

\section{Statistics and analysis}

296 The SCN half-lives and the accompanying regression statistics were determined as previously

297 described by Breen et al. (2019) using Origin 2018 (OriginLab, Northampton, MA, USA). The

298 data were fit using the exponential fitting tool to a single exponential decay function, $\left(y=A_{1} e^{\frac{-x}{t 1}}\right.$

$299+y_{0}$ ), where $\mathrm{x}$ is time, $\mathrm{y}$ is concentration, $\mathrm{y}_{0}$ is the value of the function at the asymptotic limit,

$300 \mathrm{~A}_{1}$ is the concentration maximum, and $\mathrm{t} 1$ is the reciprocal of the first-order elimination rate

301 constant $\mathrm{k}$. None of the variables were constrained and no weighting function was used. Fits

302 were to the full data set, the blood plasma concentration for each fish measured was treated as an

303 individual sample point and thus were not averaged at each sampling interval prior to fitting. The

304 reported half-life is related to the rate constant by $t_{\frac{1}{2}}=\frac{\ln 2}{k}$.

305 When a two-compartment model was employed, a graph of the natural log of the SCN blood

306 plasma concentration vs days post-exposure was constructed, and the data were divided by

307 inspection into a fast or early time component and a slow or later time component (Breen et al.

308 2019). Each component group was fit to a linear function and the half-life was calculated from

309 the resultant slope of the linear fit, $t_{\overline{1}}=\frac{\ln 2}{\text { slope }}$. 


\section{RESULTS}

\section{Cyanide Exposure}

313 Shortly after the fish were immersed in the $50 \mathrm{ppm} \mathrm{CN}$ bath, they began to swim erratically and

314 gasped for air. While in the recovery bath, a loss of balance but strong respiratory activity was

315 observed. Both $20 \mathrm{~s}$ and $45 \mathrm{~s}$ exposed fish were completely immobilized by 45 seconds after

316 initially being dipped into the $\mathrm{CN}$ bath. For the $20 \mathrm{~s}$ exposure, fish returned to normal swimming

317 behavior approximately $7 \mathrm{~min}$ after exposure while for the $45 \mathrm{~s}$, normal swimming returned by

318 approximately $17 \mathrm{~min}$, indicating that recovery time varied proportionally with the exposure

319 time. There were no mortalities in any exposure. Most exposed fish did not accept food for the

320 first 3 days post-exposure, but then ate regularly after the third day.

321 After exposure to $\mathrm{CN}$, the SCN concentration in the blood plasma was observed to increase

322 quickly over the first $6 \mathrm{hrs}$, and then begin to decrease rapidly over the next $24 \mathrm{hrs}$. The

323 maximum SCN was observed $4 \mathrm{hrs}$ post-exposure corresponding to a concentration of $468 \pm 29$

$324 \mathrm{ppb}$ for the $45 \mathrm{~s}$ exposure and $3 \mathrm{hrs}$ post-exposure corresponding to a concentration of $301 \pm 6$

$325 \mathrm{ppb}$ for the $20 \mathrm{~s}$ exposure (Fig. 1A, B). In this first CN exposure, SCN blood plasma levels began

326 to plateau at day 3 and remained elevated until the last sampling time at day $13(158 \pm 54 \mathrm{ppb})$.

327 Control fish SCN plasma levels for this trial were $(112 \pm 21 \mathrm{ppb}, \mathrm{n}=5)$. To determine when

328 SCN blood plasma levels reach control levels, a second $45 \mathrm{~s} \mathrm{CN}$ exposure was carried out. In this

329 second trial, the SCN blood plasma concentration peaked at close to $400 \mathrm{ppb}$ over the first two

330 time points sampled (4 and $13.2 \mathrm{hrs}$ ). Control levels for this exposure $(15 \pm 4 \mathrm{ppb}, \mathrm{n}=4)$ were

331 reached seven days after exposure (Fig. 1C). Between these two cyanide exposure experiments,

332 additional control fish $(n=9)$ were sampled for their SCN blood plasma levels. Eight were found

333 to be below detection limits and one was found to be $35 \mathrm{ppb}$.

334 In all CN exposures, the rate of SCN elimination was fit to a single-phase exponential decay

335 function with time constant parameters (Table 2). Regression statistics demonstrated all

336 exposures to be statistically significant when fit to a single-phase exponential decay function

337 (T1, 45 s: $\mathrm{r}^{2}=0.55$ and $\mathrm{P}<0.0001, \mathrm{~T} 1,20 \mathrm{~s}: \mathrm{r}^{2}=0.68, \mathrm{P}<0.0001, \mathrm{~T} 2,45 \mathrm{~s}: \mathrm{r}^{2}=0.86, \mathrm{P}<$

338 0.0001). The data were fit without constraining $\mathrm{y}_{0}$, and thus the concentration of SCN was not

339 forced to go to zero at infinite time. This resulted in $\mathrm{y}_{0}$ values for the first trial of $163 \mathrm{ppb} \pm 15$

340 for $45 \mathrm{~s}$ exposure and $136 \mathrm{ppb} \pm 10$ for $20 \mathrm{~s}$ exposures which are above control levels and 7.8 
$341 \mathrm{ppb} \pm 17$ for the second trial which is below control levels. In the first trial, the half-lives

342 observed were fast, dropping to a plateau level in about two days following exposure. The

343 plateau level remained for the next 13 days, and no data were obtained for times longer than 13

344 days for this trial. In the second trial, the control levels were reached quickly, no plateau was

345 observed, and the resultant half-life was $1.2 \pm 0.2$ days. In comparing the goodness of the fit

346 from trial one to trial two for the $45 \mathrm{~s}$ exposures, the trial two fit is much better than either of the

347 trial one fits, based on the reported correlation coefficients and standard errors, however this

348 could be due to the differences in the intervals in which sampling was conducted. For the first

349 trial, in order to define the curve at early times and capture SCN levels going through a

350 maximum, 8 times points were sampled in the first 3 days post-exposure. For the second $45 \mathrm{~s}$

351 trial, only 3 time points were sampled in the first 2 days. As with A. ocellaris, attempts to fit all

352 the $45 \mathrm{~s}$ exposure data to two-phase exponential fit in Origin to use a two-compartment model

353 did not converge. However, the longer half-life was determined to be $42 \pm 33$ days for the $45 \mathrm{~s}$

354 exposure using a two-compartment model (Fig. 1C insert). It is worth noting that there was an

355 outlier for the four fish sampled at the last time point at 72 days post-exposure, but the point was

356 not eliminated. The concentrations of SCN in the blood plasma for the four fish sampled at 72

357 days were found to be $12,27,33$, and $120 \mathrm{ppb} \mathrm{SCN}$. If the outlier (120 ppb) is removed, then the

358 estimate of the half-life becomes $28 \pm 16$ days and the SCN blood plasma levels have returned to

359 near control levels.

360 Thiocyanate Exposure

361 Throughout the chronic SCN exposure (100 ppm, 12 days) experiments, fish behaved normally,

362 ate well, and showed no external signs of stress. Once depuration was initiated, blood plasma

363 levels were found to be at a maximum $(44 \mathrm{ppm} \pm 2.5)$ at the initial sample time (30 min) and

364 decreased to control $(n=4)$ levels by day 15 (Fig. 2). The detection of low levels of SCN in the

365 plasma of $A$. clarkii using HPLC-UV was limited by the presence of a large neighboring peak

366 not observed in salmon or A. ocellaris plasma. Fitting of the data to a single-phase exponential

367 decay resulted in a half-life of $0.13 \pm 0.02$ days with an $\mathrm{r}^{2}$ value of 0.90 (Table 2). SCN levels in

368 holding water of these chronically exposed fish were found to be in the 20-50 ppb range for the

369 first few hours after depuration started. No SCN was detected after the first water change (24

$370 \mathrm{hrs}$ ) even though sampling continued for $72 \mathrm{hrs}$. 


\section{Holding Water}

372 A second chronic exposure trial was undertaken to further examine the holding water result. Fish

373 ( $\mathrm{n}=10)$ were exposed to SCN (100 ppm, 12 days) in a single $20 \mathrm{~L}$ polycarbonate tank, then held 374 in individual beakers during the depuration period. The results of the holding water tested for

375 SCN upon depuration from this second chronic exposure are shown in Fig. 3. A water sample

376 from each beaker was collected immediately before fish were introduced to ensure no SCN was

377 in the holding water (no-fish control). Water samples were also collected immediately after

378 introducing a fish to its beaker $(\mathrm{t}=0)$. In both instances, SCN was below our detection limit. At

379 the next sampling point, 2 hrs after the start of depuration, SCN levels in the holding water were

380 found to be at their highest level of $39 \mathrm{ppb} \pm 5$. After this time point, SCN concentrations

381 decreased continuously and, when sampled at $24 \mathrm{hrs}$ but before the first water change, no SCN

382 was detected in the holding water. Sampling continued just prior to daily water changes for two

383 additional days but no SCN in the holding water was detected at these later time points. The SCN

384 blood plasma levels were also measured for the fish used in this study. At 48 hrs, half the fish

385 were sampled, and their SCN blood plasma concentration was found to be $74 \mathrm{ppb} \pm 27$. The

386 remaining half were sampled at the final time point, $72 \mathrm{hrs}$, and the SCN blood plasma was

387 found to be $26 \mathrm{ppb} \pm 6$.

388 This observation of a steady decrease of the SCN concentration in in the holding water of a

389 depurating fish over the first $24 \mathrm{hrs}$ from an initial maximum required further investigation to see

390 if indeed, the reduction of SCN from the holding water was real and repeatable. To test this,

391 cultured fish with no known prior exposure to SCN were placed in beakers containing $500 \mathrm{~mL}$ of

392 seawater that was spiked to $20 \mathrm{ppb} \mathrm{SCN}$ and sampled over $24 \mathrm{hrs}$. The spike concentration of 20

393 ppb was much lower than the 100 ppm used in the chronic exposure studies, but was on par with

394 the concentration observed in the holding water from the earlier depuration study. When a single

395 fish was held in $500 \mathrm{~mL}$ of seawater spiked to $20 \mathrm{ppb}$, the concentration of SCN measured in the

396 holding water continually decreased over the first 24 hrs studied. Initially, the SCN concentration

397 in the water was determined to be $15 \mathrm{ppb}$ but this dropped to below our detection limit at $16 \mathrm{hrs}$

398 (Fig. 4) and remained below the detection limit until the "re-spike" after the first water change at

$39924 \mathrm{hrs}$. Here again, the SCN concentration sampled immediately after spiking was determined to

400 be $15 \pm 1$ ppb but was below our detection limit ( 1 ppb) when next sampled 24 hrs later. SCN 
401 blood plasma levels were measured for the fish used in this experiment and found to be $429 \mathrm{ppb}$ $402 \pm 164$ and $429 \mathrm{ppb} \pm 94$ at the $24 \mathrm{hr}$ and $48 \mathrm{hr}$ sampling times respectively.

403

404

405

406

407

408

409

410

411

412

413

414

415

416

417

418

419

420

421

422

423

424

425

426

427

428

\section{DISCUSSION}

\section{CN Exposure}

Amphiprion clarkii exhibited similar behavior to A. ocellaris when exposed to CN. Erratic behavior was followed by a loss of equilibrium and paralysis. In comparing these results with our previously reported work on A. ocellaris (Breen et al. 2019), the maximum level of SCN in blood plasma was decidedly lower for $A$. clarkii than for A. ocellaris while the half-lives reported were similar or smaller for $A$. clarkii depending on the exposure time (Table 3 ). The lower concentration of $\mathrm{SCN}$ in the blood plasma suggests that $A$. clarkii take up less $\mathrm{CN}$ during exposure when compared to A. ocellaris or eliminate metabolites from the blood plasma more efficiently. The half-lives reported here for acute pulsed exposure in marine fish are in reasonable agreement with those reported for mammals using intravenous or subcutaneous injections (0.21-8.0 days) (Logue et al. 2010).

In the first $\mathrm{CN}$ exposure trial, the measured half-life of the $45 \mathrm{~s}$ exposure appears faster than the $20 \mathrm{~s}$ exposure, contrary to those results for A. ocellaris. However, the large Relative Standard Deviations $(40 \%, 30 \%)$ associated with these data make us hesitant to draw any dramatic conclusions. Our second $45 \mathrm{~s}$ trial, which had a much lower RSD than the first $45 \mathrm{~s}$ trial (17\% vs. $40 \%$ ), resulted in a half-life similar to that observed for A. ocellaris. The goal of the second trial was to establish when control levels were reached, and because of this, there were only 3 time points sampled within the first three days of depuration. Trial $1 \mathrm{CN}$ exposures were sampled at 8 time points over the first three days, and have a large variability, resulting in a less robust fit of the elimination from the blood plasma because of natural variability.

In the first trial of the current study, the elimination of SCN from the blood plasma plateaued at approximately $150 \mathrm{ppb}$ starting at 4 and $12 \mathrm{hrs}$ for each exposure time respectively. Likewise, in A. ocellaris, $\mathrm{SCN}$ concentrations in the blood plasma plateaued at approximately $500 \mathrm{ppb}$ for both 20 and $45 \mathrm{~s}$ exposure times beginning at two and four days respectively (Breen et al. 2019). 
429 The lower plateau in this study is likely due to the shorter half-life and initial lower levels of 430 SCN observed in their plasma.

431 Vaz et al. (2012) exposed A. clarkii $(1.8 \pm 0.2 \mathrm{~g})$ to $25 \mathrm{ppm} \mathrm{CN}$ for 60 seconds and reported a $43233 \%$ mortality rate. We did not observe any mortality when fish were exposed to $\mathrm{CN}$ 433 concentrations of $50 \mathrm{ppm} \mathrm{CN}$ for 45 seconds. However, this difference in vulnerability could be 434 due to differences in fish size, health and/or stress level (Hanawa et al. 1998). When assessing 435 the vulnerability of A. ocellaris to CN, Madeira et al. (2020) found that larger fish had a higher 436 survival rate and quicker recovery time when exposed for the same time and concentration of $\mathrm{CN}$ 437 as their smaller conspecifics. As the fish used in our study were larger than those in the Vaz et al. 438 (2012) study, a lower mortality rate would be expected.

439 SCN Exposure

440 As with the $\mathrm{CN}$ exposure, when the results for $A$. clarkii were compared with those previously 441 reported for A. ocellaris (Breen et al. 2019), the SCN blood plasma level was much lower. Both 442 species were exposed to $100 \mathrm{ppm} \mathrm{SCN}$ bath for 11-12 days, but the maximum SCN blood 443 plasma was $44 \mathrm{ppm} \pm 2.5$ for $A$. clarkii, while that for $A$. ocellaris was at $220 \mathrm{ppm} \pm 31$ (Table 444 3). The SCN levels in the blood plasma of $A$. clarkii were half that of the exposure bath, while 445 those observed for $A$. ocellaris were twice that of the exposure bath. It appears that even under 446 different exposure conditions (pulsed CN versus chronic SCN), A. clarkii have lower levels of $447 \mathrm{SCN}$ in their blood plasma, indicating that they uptake less $\mathrm{CN} / \mathrm{SCN}$ during exposure than $A$. 448 ocellaris or eliminate SCN from their blood more efficiently.

449 The half-life for SCN clearance in the blood plasma measured for A. clarkii when chronically 450 exposed to SCN was more than two times shorter when compared to A. ocellaris. In a similar 451 experiment on the freshwater fish rainbow trout (Oncorhynchus mykiss) the reported half-life for 452 clearance of $\mathrm{SCN}$ from their blood was 2.02 or 2.36 days depending on the model used (Brown 453 et al. 1995). This was much slower than our reported value of $0.13 \pm 0.02$ days and could reflect 454 the differences in the osmoregulatory systems of marine versus freshwater fish.

455 The continued failure to replicate the work of Vaz et al. (2012) calls to question the ultimate fate 456 of CN and SCN in marine fish (Breen et al. 2019; Breen et al. 2018). We have now confirmed in 457 two marine species that $\mathrm{CN}$ is converted to SCN quickly as evidenced by the rapid rise of SCN 
458 in the blood plasma following $\mathrm{CN}$ exposure, which is also in accordance with the mammalian 459 model. The clearance rate of SCN from the blood plasma is also fast, with the highest levels 460 depleted within the first few days of $\mathrm{CN}$ exposure, also in accordance with mammalian models.

461 However, the question remains where does the SCN go? Despite multiple attempts, SCN was 462 not detected in the holding water of fish acutely exposed to $\mathrm{CN}$, but elevated levels of SCN in 463 the blood plasma were observed after CN exposure. (Breen et al. 2018, Breen et al. 2019). Is the 464 failure to detect $\mathrm{SCN}$ in the holding water of marine fish post-acute exposure to $\mathrm{CN}$ because they 465 are not excreting SCN, or is it because any excretion by a small fish in a relatively large quantity 466 of water is diluted to concentrations below the detection limit?

\section{Holding Water}

468 Blood plasma levels for $A$. clarkii of SCN following acute exposure to $\mathrm{CN}$ were found to be in 469 the range of $500 \mathrm{ppb}$ at their maximum but decreased rapidly after exposure. Levels above this are unlikely to be observed as higher $\mathrm{CN}$ doses would be required, leading to an increase in mortality rather than higher levels of SCN in the blood plasma (Breen et al. 2019; Madeira et al. 2020). In order to increase SCN blood plasma levels and thus enhance the likelihood of detecting

$473 \mathrm{SCN}$ in the holding water of a marine fish, A. clarkii were exposed to $100 \mathrm{ppm} \mathrm{SCN}$ for 12 days and allowed to depurate in only $500 \mathrm{~mL}$ of holding water. Under such conditions, blood plasma 475 levels were found to be close to $50 \mathrm{ppm}$ for $A$. clarkii, approximately 100 times higher than the 476 highest blood plasma SCN concentration observed in fish exposed to CN. Under these optimized conditions for recovery, $\mathrm{SCN}$ was detected in the holding water of these chronically exposed, 478 depurating fish. The observed levels of SCN in the holding water were 1000 times less than SCN 479 blood plasma levels in chronically exposed A. clarkii (Fig. 2) and 2000 times less than the SCN 480 concentration used for chronic exposure. Most surprisingly, SCN holding water levels sharply decreased from $40 \mathrm{ppb}$ observed at $2 \mathrm{hrs}$ to undetectable levels within the first $24 \mathrm{hrs}$ of depuration. Sampling continued before each water change for two additional days, but no further SCN was detected in the holding water even though SCN blood plasma levels were found to be $74 \mathrm{ppb} \pm 27$ at $48 \mathrm{hrs}$ and $26 \mathrm{ppb} \pm 6$ at $72 \mathrm{hrs}$ for the depurating fish. The decrease in SCN concentration in the holding water of $A$. clarkii while depurating demonstrated that $A$. clarkii 
487 continually release SCN to their holding water, even when SCN remains elevated in their blood 488 plasma.

489 While the source of the SCN detected $2 \mathrm{hrs}$ after introducing the fish is unknown, once the SCN 490 is introduced to the holding water, it is likely re-absorbed into the fish as it is no longer present in

491 the water. Breen et al. (2018) ruled out container effects and demonstrated that SCN

492 concentrations were stable in control beakers without fish. It was also observed that SCN

493 concentrations were significantly reduced with beakers containing a fish, A. ocellaris. (Breen et

494 al. 2018). The most likely explanation for this uptake of SCN is either via diffusion across the

495 gills or through the intestines via the drinking response. However, drinking rates in marine fish

496 that have been reported range from $2-7 \mathrm{~mL} / \mathrm{kg}$ per hour making it implausible for the fish to

497 drink $500 \mathrm{~mL}$ of holding water in less than $24 \mathrm{hrs}$ leaving the gills as the likely site of entry.

498 (Fuentes \& Eddy 1997; Grosell 2019; Perrott et al. 1992). This study was not designed to

499 determine the mechanism of the removal of SCN from holding water by fish, and further work is

500 required to determine the removal mechanism(s).

501 Our results of holding water spiked with trace levels of SCN demonstrate that with a fish present,

502 the SCN concentration decreases to below detection within the $24 \mathrm{hr}$ period after the spike. This

503 removal of SCN from the holding water is accompanied by elevated levels of SCN in the blood

504 plasma. Our holding water results are in marked contrast to Vaz et al. (2012) who claimed that

505 fish pulse-exposed to $25 \mathrm{ppm} \mathrm{CN}$ excreted SCN starting at day 2 and excretion continued even

506 with daily water changes through their 28 day observation period without decreasing. They

507 reported an initial increase and then a plateau of SCN in holding water at $9.84 \pm 0.03 \mathrm{ppb}$. In our

508 study, SCN was detected in the holding water for only the chronically exposed A. clarkii likely

509 due to the higher SCN blood plasma (100x) levels than when CN exposed. The measured SCN in

510 the holding water was only observed for the first few hours once depuration started, as this is

511 when the SCN in the blood plasma is at its maximum and we again note that the SCN

512 concentration in the holding water was 1000x less than the measured SCN in the blood plasma

513 during these early times. As detailed by Breen et al. (2018), the amount of SCN that Vaz et al.

514 (2012) claimed their CN exposed fish excreted is too high and we again reject the notion that

$515 \mathrm{SCN}$ can be detected in the aquaria water of CN exposed fish, not at Day 2 nor at Day 28. 
516 It has often been erroneously suggested that cyanide metabolites are excreted out of the fish via

517 urine following CN exposure (Vaz et al. 2012) as in mammalian models (Bruckner \& Roberts

518 2008; Lanno \& Dixon 1996; Logue et al. 2010; Nelson 2006). It is widely accepted that the

519 mechanism of uptake and elimination of ions from marine teleost depends on the charge of the

520 ion. Uptake of monovalent anions occurs from diffusion across the gills and transport in the

521 intestines. Excretion of monovalent anions is accomplished by active transport via chloride cells

522 in the gills (Greenwell et al. 2003). Divalent ions enter via the drinking response but are excreted

523 in the urine $\left(\mathrm{SO}_{4}{ }^{2-}, \mathrm{Mg}^{2+}\right)$ or fecal matter $\left(\mathrm{Ca}^{2+}\right)$ (Evans 2008; Grosell 2019; Hickman Jr 1968;

524 Whittamore 2012). There is no evidence that the urine is the primary pathway to eliminate

525 monovalent anions in marine teleost (Whittamore 2012).

526 This difference in SCN elimination compared to mammalian models is due to the

527 osmoregulation strategy of marine fish. To maintain osmotic balance with the surrounding water,

528 marine fish have a low urinary excretion rate in order to retain water in their blood. The urine

529 flow rates in marine teleosts are $1-2 \%$ of body weight daily because water is highly conserved

530 and can be reabsorbed by the urinary bladder (Evans 1993). However, while we demonstrate that

$531 \mathrm{SCN}$ is rapidly eliminated from blood plasma, the terminal fate of SCN ions in the body of

532 marine fish remains unknown but must be consistent with the mechanisms of monovalent ions.

533 The data presented here demonstrate that marine fish can remove trace quantities of SCN from

534 the holding water and retain it. This further corroborates the findings that testing for SCN in the

535 holding water of this fish is not a viable indicator of CN exposure (Breen et al. 2019; Breen et al.

536 2018; Herz et al. 2016), opposing previous studies (Vaz et al. 2017; Vaz et al. 2012). This also

537 nullifies any concern of false positives of non-exposed fish during cohabitation with CN exposed

538 fish.

539 The results of the $A$. clarkii SCN half-life following CN exposure suggest a two-compartment

540 model for SCN elimination similar to that of $A$. ocellaris in that a fast and slow elimination

541 component was observed (Breen et al. 2019; Toutain \& Bousquet-Mélou 2004). Two-

542 compartment models are commonly used in pharmaceutical research for drug metabolism (Ishida

543 et al. 2016; Metzler 1971). In both of these species of marine fish, $\mathrm{CN}$ is absorbed through the

544 gills and/or the gut via the drinking response and is quickly metabolized into SCN as evidenced

545 by the rise in SCN blood plasma levels. We speculate that the tissue may be acting as a SCN

Peer] reviewing PDF | (2020:04:48457:2:0:NEW 3 Oct 2021) 
546 reservoir. If this is the case, then $\mathrm{SCN}$ stored in the tissue of fish could potentially serve as an

547 indicator of $\mathrm{CN}$ exposure but further studies quantifying SCN levels in the tissue of marine fish 548 exposed to $\mathrm{CN}$ would need to be conducted.

549 In order to properly validate a test for CN exposure by the presence of SCN, it is also critical to 550 know the baseline values of SCN in the blood and tissue of non-cyanide caught fish from the 551 areas where $\mathrm{CN}$ is likely used. Fish in the Indo Pacific region may be exposed to very low 552 concentrations of $\mathrm{CN}$ or SCN from natural sources, such as cyanogenic foods, foods rich in SCN, 553 or anthropogenic sources, predominantly runoff from industrial processes such as mining.

554 Therefore, these fish may already have significant SCN levels in their blood and/or tissues. The 555 present findings confirm the blood plasma SCN maybe be a useful biomarker of CN exposure in 556 marine fish if measured shortly after exposure. Additional species from a broader taxonomic 557 sample must be evaluated prior to any definitive conclusions.

558

559

ACKNOWLEDGEMENTS

560

561 We would like to thank the current and former undergraduates from Roger Williams University 562 who have been involved in this project, especially Julia Grossman, Gabbie Baillargeon, Hannah 563 Sterling, Natalie Danek, Julia Dwyer, and Sara Hunt. Kevin Erickson of MASNA provided 564 thoughtful comments on an earlier draft of this manuscript. We also thank the reviewers for their 565 helpful comments and insight. Sea \& Reef Aquaculture of Maine U.S.A. provided a portion of 566 the fish used in these experiments. 
567

568

569

570

571

572

573

574

575

576

577

578

579

580

581

582

583

584

585

586

587

588

589

590

591

592

593

594

595

596

597

598

599

600

601

602

603

604

605

606

607

608

609

610

611

612

\section{REFERENCES}

Balboa CM. 2017. Mission interference: How competition confounds accountability for environmental nongovernmental organizations. Review of Policy Research 34:110-131.

Barber CV, and Pratt VR. 1997. Sullied seas: Strategies for combating cyanide fishing in Southeast Asia and beyond. Washington DC: World Resources Institute and International Marinelife Alliance.

Bellwood DR. 1981. Cyanide... An investigation into the long term histological effects of sodium cyanide doses upon the gastro-intestinal tract of Dascyllus trimaculatus. Part One. Freshwater and Marine Aquarium 4:31-35.

Bhandari RK, Manandhar E, Oda RP, Rockwood GA, and Logue BA. 2014. Simultaneous highperformance liquid chromatography-tandem mass spectrometry (HPLC-MS-MS) analysis of cyanide and thiocyanate from swine plasma. Analytical and bioanalytical chemistry 406:727-734.

Blanchard J. 1981. Evaluation of the relative efficacy of various techniques for deproteinizing plasma samples prior to high-performance liquid chromatographic analysis. Journal of Chromatography B: Biomedical Sciences and Applications 226:455-460.

Breen NE, Bonanno JA, Hunt S, Grossman J, Brown J, Nolte H, and Rhyne AL. 2019. On the half-life of thiocyanate in the plasma of the marine fish Amphiprion ocellaris: implications for cyanide detection. PeerJ 7:e6644.

Breen NE, Lowenstein J, Metivier R, Andrade L, and Rhyne AL. 2018. Can excreted thiocyanate be used to detect cyanide exposure in live reef fish? PloS ONE, 13:e0196841.

Brown D, Lanno RP, Vandenheuvel MR, and Dixon DG. 1995. HPLC determination of plasma thiocyanate concentrations in fish blood: application to laboratory pharmacokinetic and field-monitoring studies. Ecotoxicology and environmental safety 30:302-308.

Bruckner A, and Roberts G. 2008. Proceedings of the International Cyanide Detection Testing Workshop. Silver Spring, MD: NOAA Technical Memorandum, NMFS-OPR-40.

Bruno JF, and Selig ER. 2007. Regional decline of coral cover in the Indo-Pacific: timing, extent, and subregional comparisons. PLoS ONE, 2:e711.

Burke L, Reytar K, and Spalding M. 2012. Reefs at risk revisited in the Coral Triangle. Washington DC: World Resources Institute

Cervino JM, Hayes RL, Honovich M, Goreau TJ, Jones S, and Rubec PJ. 2003. Changes in zooxanthellae density, morphology, and mitotic index in hermatypic corals and anemones exposed to cyanide. Marine Pollution Bulletin 46:573-586.

Dalabajan D. 2005. Fixing the broken net: Improving enforcement of laws regulating cyanide fishing in the Calamianes Group of Islands, Philippines. SPC live reef fish information bulletin 15:3-12.

Davis S, Murray J, and Katsiadaki I. 2017. Cyanide in the aquatic environment and its metabolism by fish: A desk-based review. Suffolk, England: Centre for Environment, Fisheries and Aquaculture Science.

Day B, Borowitz J, Mukhopadhyay S, and Isom G. 2018. Sulfurtransferase enzymes involved in cyanide metabolism. In: McQueen C, ed. Comprehensive Toxicology. 3rd Edition ed: Elsevier, 541-556.

Descombes P, Wisz MS, Leprieur F, Parravicini V, Heine C, Olsen SM, Swingedouw D, Kulbicki M, Mouillot D, and Pellissier L. 2015. Forecasted coral reef decline in marine biodiversity hotspots under climate change. Global Change Biology 21:2479-2487. $10.1111 / \mathrm{gcb} .12868$ 
613 Dietzel A, Bode M, Connolly SR, and Hughes TP. 2020. Long-term shifts in the colony size 614 structure of coral populations along the Great Barrier Reef. Proceedings of the Royal

Erdmann MV. 1999. Clove oil: an 'eco-friendly'alternative to cyanide use in the live reef fish industry. SPC live reef fish information bulletin 5:4-7.

Evans D. 1993. Osmotoc and ionic regulation. In: Evans, ed. The physiology of fishes. Boca Raton: CRC Press, 315-341.

Evans DH. 2008. Teleost fish osmoregulation: what have we learned since August Krogh, Homer Smith, and Ancel Keys. American Journal of Physiology-Regulatory, Integrative and Comparative Physiology 295:R704-R713.

Frey JB. 2013. A community-based approach to sustainable ornamental fishing on coral reefs. D. Phil. Thesis, University of Manitoba (Canada), Bali

Fuentes J, and Eddy F. 1997. Drinking in marine, euryhaline and freshwater teleost fish. In: Hazon N, Eddy FB, Flik G, eds. Ionic Regulation in Animals Berlin: Springer, 135-149.

Graham T. 2001. A collaborative strategy to address the live reef food fish trade. Washington DC: World Resources Institute, The Nature Conservancy, International Marinelife Alliance, and the MacArthur Foundation.

Greenwell MG, Sherrill J, Clayton LA. 2003. Osmoregulation in fish. Veterinary Clinics of North America: Exotic Animal Practice 6:169-189.

Grosell M. 2019. Intestinal transport processes in marine fish osmoregulation. In: Baldisserotto B MJ, and Kapoor BG, eds. Fish Osmoregulation: Boca Raton: CRC Press, 333-357.

Hall K, and Bellwood DR. 1995. Histological effects of cyanide, stress and starvation on the intestinal mucosa of Pomacentrus coelestis, a marine aquarium fish species. Journal of Fish Biology 47:438-454.

Hanawa M, Harris L, Graham M, Farrell AP, and Bendell-Young L. 1998. Effects of cyanide exposure on Dascyllus aruanus, a tropical marine fish species: lethality, anaesthesia and physiological effects. Aquarium Sciences and Conservation 2:21-34.

Herz N, Ferse S, Alfiansah YR, and Kunzmann A. 2016. High-performance liquid chromatography to detect thiocyanate in reef fish caught with cyanide: A practical field application. SPC live reef fish information bulletin 21:8-16.

Hickman Jr CP. 1968. Ingestion, intestinal absorption, and elimination of seawater and salts in the southern flounder, Paralichthys lethostigma. Canadian journal of zoology 46:457466.

Hoegh-Guldberg O. 1999. Climate change, coral bleaching and the future of the world's coral reefs. Marine and freshwater research 50:839-866.

Hughes TP, Barnes ML, Bellwood DR, Cinner JE, Cumming GS, Jackson JB, Kleypas J, Van De Leemput IA, Lough JM, and Morrison TH. 2017. Coral reefs in the Anthropocene. Nature 546:82-90.

Ishida M, Kitagawa K, Ichihara T, Natsume T, Nakayama R, Nagasawa N, Kubooka M, Ito T, Uno M, and Goto Y. 2016. Underestimation of myocardial blood flow by dynamic perfusion CT: explanations by two-compartment model analysis and limited temporal sampling of dynamic CT. Journal of Cardiovascular Computed Tomography 10:207-214.

Jones RJ, and Hoegh-Guldberg O. 1999. Effects of cyanide on coral photosynthesis: implications for identifying the cause of coral bleaching and for assessing the environmental effects of cyanide fishing. Marine Ecology Progress Series 177:83-91. 
658

659

660

661

662

663

664

665

666

667

668

669

670

671

672

673

674

675

676

677

678

679

680

681

682

683

684

685

686

687

688

689

690

691

692

693

694

695

696

697

698

699

700

701

Lanno RP, and Dixon DG. 1996. The comparative chronic toxicity of thiocyanate and cyanide to rainbow trout. Aquatic toxicology 36:177-187.

Lewis WM, and Tarrant Jr RM. 1960. Sodium cyanide in fish management and culture. The Progressive Fish-Culturist 22:177-180.

Logue BA, Hinkens DM, Baskin SI, and Rockwood GA. 2010. The analysis of cyanide and its breakdown products in biological samples. Critical Reviews in Analytical Chemistry 40:122-147.

Losada S, and Bersuder P. 2017. Methods of detecting cyanide, thiocyanate and other byproducts in seawater: A desk-based assessment. Suffolk, England: Centre for Environment, Fisheries and Aquaculture Science.

Madeira D, Andrade J, Leal MC, Ferreira V, Rocha RJM, Rosa R, and Calado R. 2020. Synergistic Effects of Ocean Warming and Cyanide Poisoning in an Ornamental Tropical Reef Fish. Frontiers in Marine Science 7:246. 10.3389/fmars.2020.00246

Mak KK, Yanase H, and Renneberg R. 2005. Cyanide fishing and cyanide detection in coral reef fish using chemical tests and biosensors. Biosensors and Bioelectronics 20:2581-2593.

Manipula BE, Suplido ER, and Astillero NM. 2001. Standard Operating Procedures For Cyanide Testing Used By The Philippines Cyanide Detection Test (CDT) Network. Manlia: Philippines Department of Agriculture-Bureau of Fisheries and Aquatic Resources / International Marinelife Alliance.

Metzler CM. 1971. Usefulness of the two-compartment open model in pharmacokinetics. Journal of the American Statistical Association 66:49-53.

Muñoz-Muñoz AC, Pekol T, Schubring D, Johnson C, and Andrade L. 2017. Identification of Novel Opioid Interferences using High-Resolution Mass Spectrometry. Journal of analytical toxicology 42:6-16. 10.1093/jat/bkx065

Murray JM, Bersuder P, Davis S, and Losada S. 2020. Detecting illegal cyanide fishing: Establishing the evidence base for a reliable, post-collection test. Marine Pollution Bulletin 150:110770.

Nelson L. 2006. Acute cyanide toxicity: mechanisms and manifestations. Journal of Emergency Nursing 32:S8-S11.

Perrott M, Grierson C, Hazon N, and Balment R. 1992. Drinking behaviour in sea water and fresh water teleosts, the role of the renin-angiotensin system. Fish Physiology and Biochemistry 10:161-168.

Pyle R. 1993. Marine aquarium fish. In: Wright A, and Hill L, eds. Nearshore marine resources of the South Pacific: Information for fisheries development and management. Suva, Fiji; Honiara, Solomon Islands; Canada: Institute of Pacific Studies; Forum Fisheries Agency; International Centre for Ocean Development, 135-176.

Reaka-Kudla ML. 1997. The global biodiversity of coral reefs: a comparison with rain forests. Biodiversity II: Understanding and protecting our biological resources 2:551.

Rhyne AL, Tlusty MF, Schofield PJ, Kaufman L, Morris JA, and Bruckner AW. 2012. Revealing the Appetite of the Marine Aquarium Fish Trade: The Volume and Biodiversity of Fish Imported into the United States. PloS ONE 7:e35808. 10.1371/journal.pone.0035808

Rhyne AL, Tlusty MF, Szczebak JT, and Holmberg RJ. 2017. Expanding our understanding of the trade in marine aquarium animals. PeerJ 5:e2949.

Peerj reviewing PDF | (2020:04:48457:2:0:NEW 3 Oct 2021) 
702

703

704

705

706

707

708

709

710

711

712

713

714

715

716

717

718

719

720

721

722

723

724

725

726

727

728

729

730

731

732
Rong L, Lim L, and Takeuchi T. 2005. Determination of iodide and thiocyanate in seawater by liquid chromatography with poly (ethylene glycol) stationary phase. Chromatographia 61:371-374.

Rubec PJ. 1986. The effects of sodium cyanide on coral reefs and marine fish in the Philippines. In: Maclean JL DL, Hosillos LV, editor. The First Asian Fisheries Forum: Manila, Philippines: Asian Fisheries Society. 297-302.

Rubec PJ, Cruz F, Pratt V, Oellers R, McCullough B, and Lallo F. 2001. Cyanide-free net-caught fish for the marine aquarium trade. Aquarium Sciences and Conservation 3:37-51.

Rubec PJ, Pratt VR, McCullough B, Manipula B, Alban J, Espero T, and Supildo E. 2003. Trends determined by cyanide testing on marine aquarium fish in the Philippines. In: Cato JC, Brown CL, editors. Marine Ornamental Species: Collection, Culture \& Conservation. Iowa City, Iowa: Iowa State Press, 327-340.

Toutain P-L, and Bousquet-Mélou A. 2004. Plasma terminal half-life. Journal of veterinary pharmacology and therapeutics 27:427-439.

Vaz MC, Esteves VI, and Calado R. 2017. Live reef fish displaying physiological evidence of cyanide poisoning are still traded in the EU marine aquarium industry. Scientific reports 7, 6566

Vaz MC, Rocha-Santos TA, Rocha RJ, Lopes I, Pereira R, Duarte AC, Rubec PJ, and Calado R. 2012. Excreted thiocyanate detects live reef fishes illegally collected using cyanide - a non-invasive and non-destructive testing approach. PLOS ONE 7:e35355.

Whittamore JM. 2012. Osmoregulation and epithelial water transport: lessons from the intestine of marine teleost fish. Journal of Comparative Physiology B 182:1-39. 10.1007/s00360011-0601-3

Youso SL, Rockwood GA, and Logue BA. 2012. The analysis of protein-bound thiocyanate in plasma of smokers and non-smokers as a marker of cyanide exposure. Journal of analytical toxicology 36:265-269. 


\section{Figure 1}

The SCN blood plasma concentration during depuration in Amphiprion clarkii after exposure to $50 \mathrm{ppm} \mathrm{CN}$.

Trial 1 (A) $20 \mathrm{~s}$ and (B) $45 \mathrm{~s}$ with sampling out to 13 days and trial 2 (C) $45 \mathrm{~s}$ with sampling out to 72 days. The black solid line represents the fit of the data to a single-phase exponential decay function. Gray data points represent early time points where SCN plasma levels are increasing and are therefore not included in the fit. Each data point indicates the mean \pm S.E. The dashed gray lines represent the average SCN concentration in control fish for a given exposure. Where no error bar is observed the error is smaller than the data point. Inset is the natural log of SCN blood plasma concentration as a function of time and includes both trials of $45 \mathrm{~s}$ exposure data. These data were divided into two groups and a linear fit was performed on both the fast (blue) and slow (red) component of SCN elimination. 

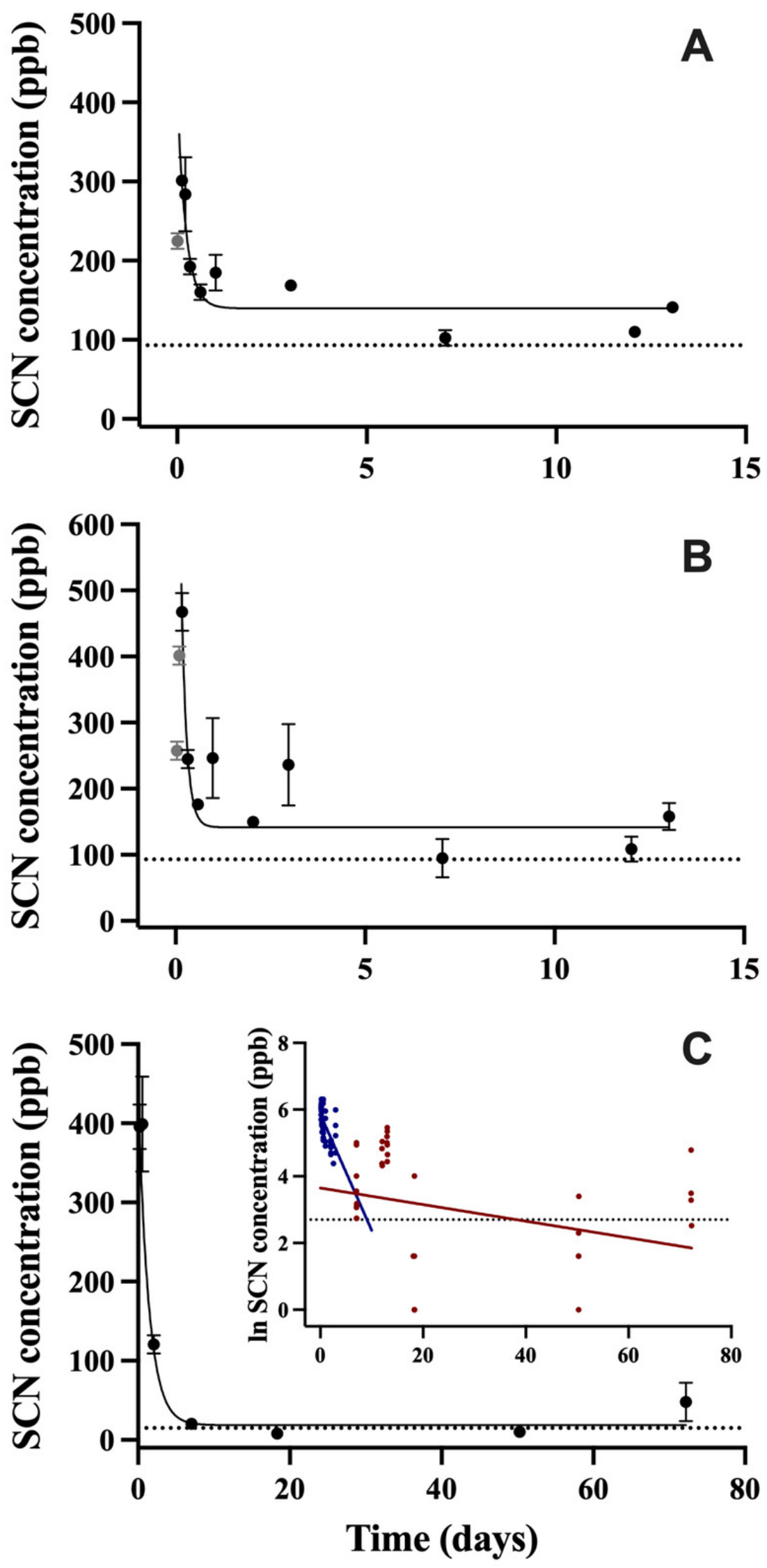
Figure 2

The SCN blood plasma concentration during depuration for Amphiprion clarkii after exposure to $100 \mathrm{ppm} \mathrm{SCN}$ for 12 days.

The black solid line represents the fit of the data to a single-phase exponential decay function. Each data point indicates the mean \pm S.E. Where no error bar is observed the error is smaller than the data point. Inset shows later time points.

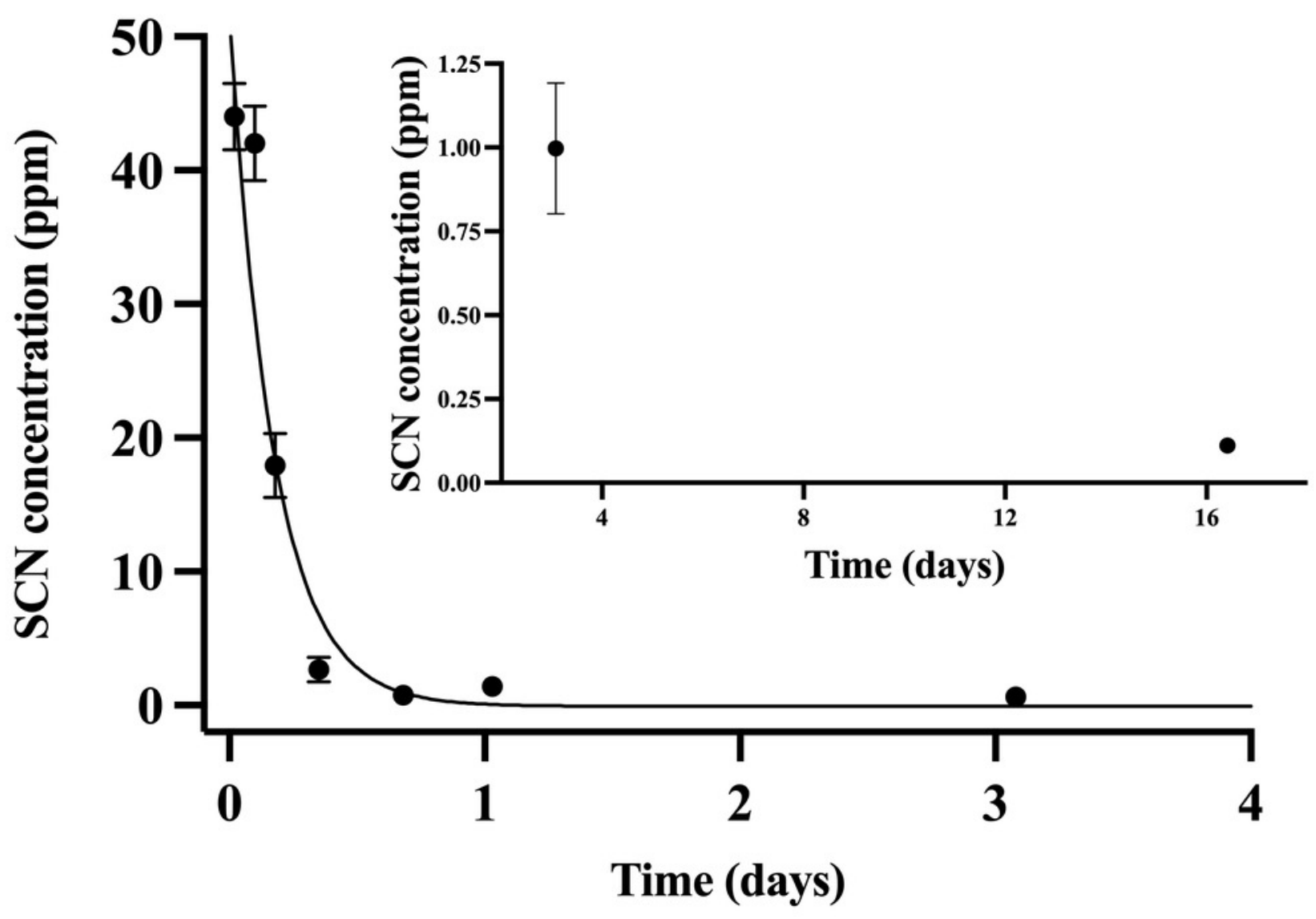


Figure 3

The average $(n=10)$ concentration of $S C N$ detected in $0.5 \mathrm{~L}$ of holding water containing a single Amphiprion clarkii depurating for $72 \mathrm{hrs}$ after exposure to 100 ppm SCN for 12 days.

The data points indicate the mean \pm S.E of the SCN concentration in the holding water.

Circles are samples once depuration had begun; the square indicates the measured concentration of SCN in the holding water just prior to the addition of the fish. Where no error bar is observed the error is smaller than the data point.

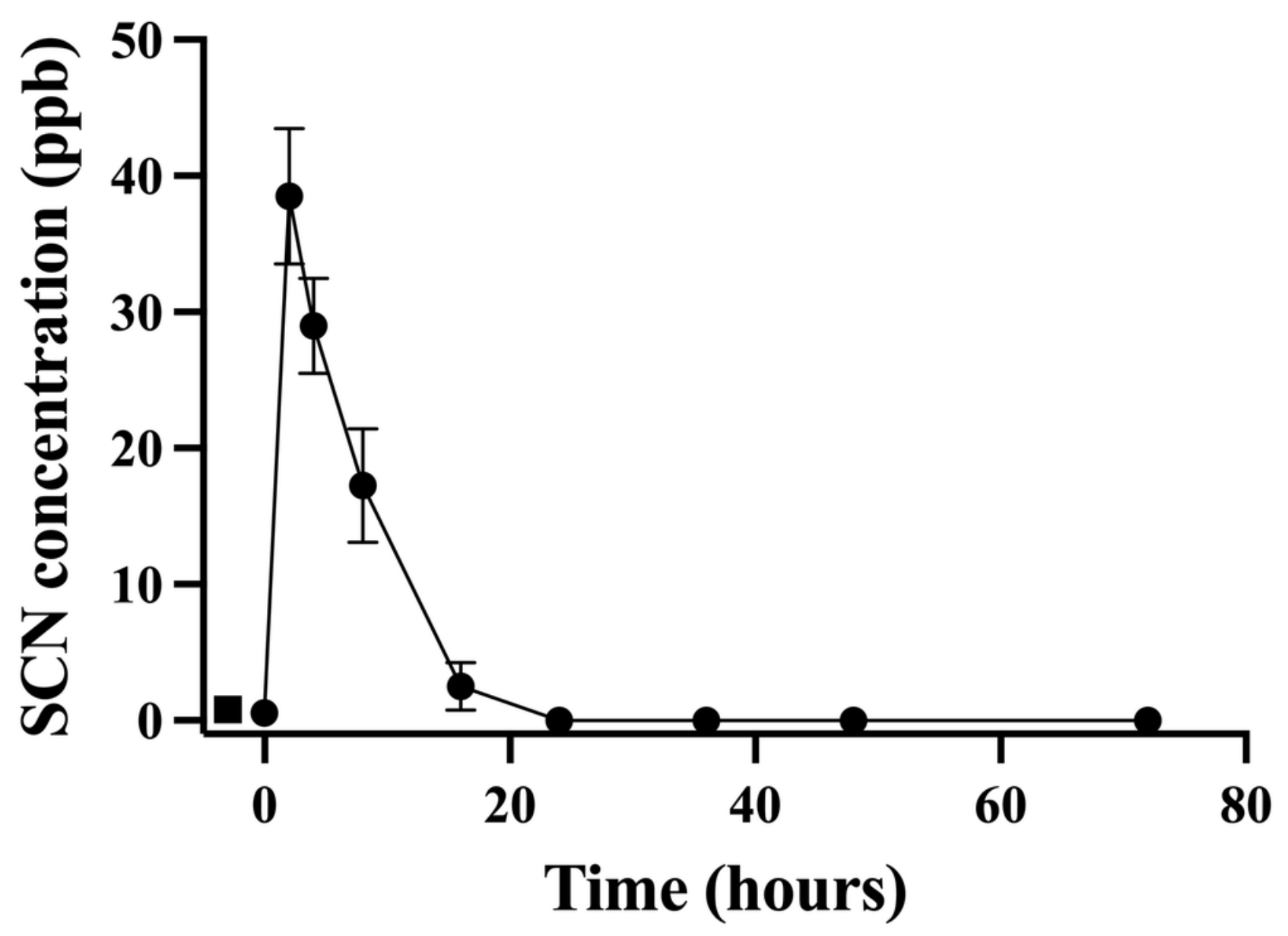


Figure 4

The average $(n=10)$ concentration of SCN detected in $0.5 \mathrm{~L}$ of holding water spiked with SCN containing 1 non-exposed Amphiprion clarkii.

Each data point indicates the mean \pm S.E. Where no error bar is observed the error is smaller than the data point. The round data points indicate the data collected after the initial SCN spike $(t=0)$. The square data points indicate the data after a water change at $24 \mathrm{hrs}$ followed by a second spike

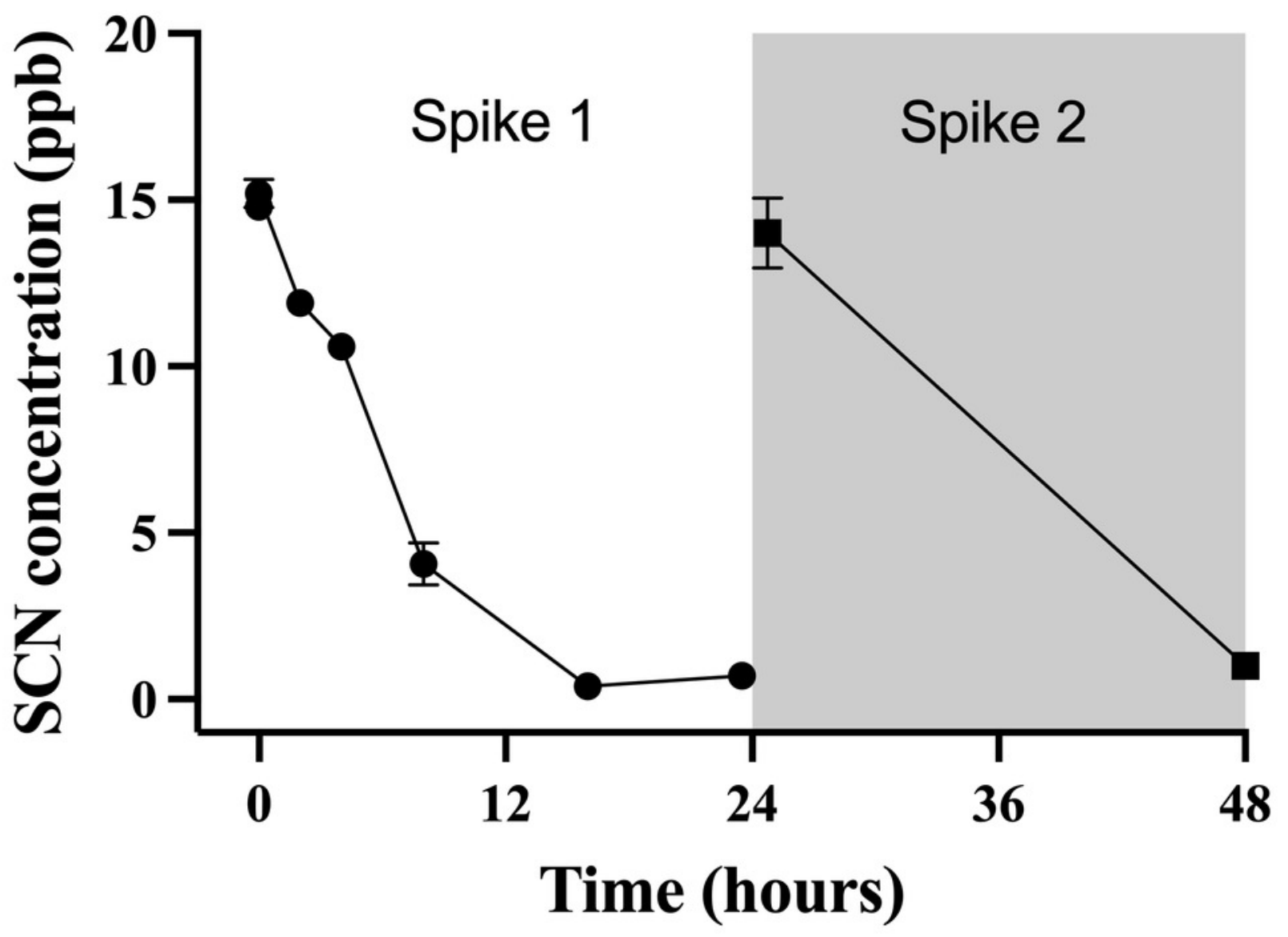




\section{Table $\mathbf{1}$ (on next page)}

Average weight ( + 1 S.D.) and sample size (n) of Amphiprion clarkii exposed to 50 ppm $\mathrm{CN}$ for either 20 or 45 seconds across 2 trials and 100 ppm for 12 day.

There were two groups (small/large) of Amphiprion clarkii used for CN 2 trial however fish size did not affect SCN half-life. 
Table 1. Average weight, sample size (n), and controls of Amphiprion clarkii pulse exposed to an acute dosage of 50 ppm CN for either 20 or 45 seconds across 2 trials and 2 chronic exposures of 100 ppm for 12 days. There were two groups (small/large) of Amphiprion clarkii used for CN 2 trial however fish size did not affect SCN half-life.

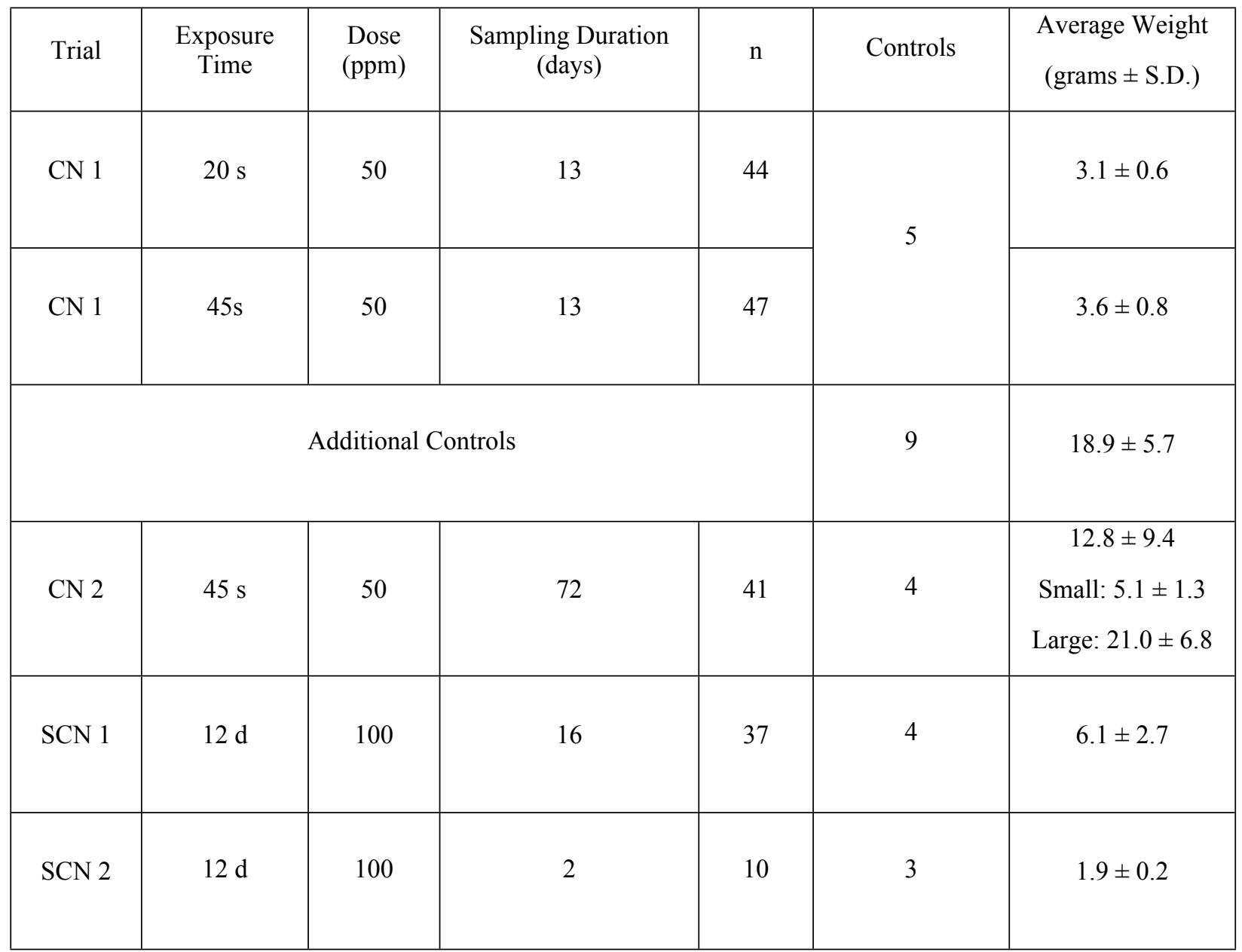




\section{Table 2 (on next page)}

Half-life results of two acute CN exposure trials and one chronic SCN exposure.

The fit (S.E.) to the function of the plasma SCN concentrations in Amphiprion clarkii exposed to $50 \mathrm{ppm} \mathrm{CN}$ or $100 \mathrm{ppm} \mathrm{SCN}$. $\mathrm{k}$ and $\mathrm{t}_{1 / 2}$ are calculated from the fit parameter $\mathrm{t}_{1}$. 
1 Table 2. The results of the fit of SCN blood plasma concentration versus time to the function

$2 y=A_{1} e^{\frac{-x}{t 1}}+y_{0}$ in order to determine the elimination half-life of SCN from the blood plasma of 3 Amphiprion clarkii for both acute exposure to $\mathrm{CN}$ chronic exposure to SCN. The standard errors 4 reported with the fit results are also given. $k$ and $t_{1 / 2}$ are calculated from the fit parameter $t_{1}$.

\begin{tabular}{|c|c|c|c|c|}
\hline Parameter & $\begin{array}{c}45 \text { s exposure } \\
\text { trial } 1\end{array}$ & $\begin{array}{c}20 \text { s exposure, } \\
\text { trial } 1\end{array}$ & $\begin{array}{c}45 \text { s exposure, } \\
\text { trial } 2\end{array}$ & $\begin{array}{c}\text { SCN exposure } \\
\text { trial } 1\end{array}$ \\
\hline $\mathrm{t}_{1 / 2}$ (days) & $0.10 \pm 0.04$ & $0.20 \pm 0.06$ & $1.2 \pm 0.2$ & $0.13 \pm 0.02$ \\
\hline$Y_{0}(p p b)$ & $163 \pm 15$ & $136 \pm 10$ & $7.8 \pm 17$ & $-580 \pm 1700$ \\
\hline$A_{1}(p p b)$ & $880 \pm 390$ & $261 \pm 54$ & $468 \pm 35$ & $55000 \pm 4000$ \\
\hline t1 (days) & $0.14 \pm 0.06$ & $0.29 \pm 0.09$ & $1.7 \pm 0.3$ & $0.19 \pm 0.03$ \\
\hline k (days $\left.{ }^{-1}\right)$ & $6.9 \pm 2.7$ & $3.5 \pm 1.0$ & $0.58 \pm 0.09$ & $5.3 \pm 0.8$ \\
\hline$r^{2}$ & 0.55 & 0.683 & 0.86 & 0.90 \\
\hline$P$ & $P<0.0001$ & $P<0.0001$ & $P<0.0001$ & $P<0.0001$ \\
\hline $\mathrm{n}$ & 47 & 44 & 41 & 37 \\
\hline
\end{tabular}




\section{Table 3 (on next page)}

Summary of SCN half-lives in fish exposed to $\mathrm{CN}$ or $\mathrm{SCN}$ including relative standard deviation (RSD) and average fish weight.

Summary of max concentration of SCN observed in fish exposed to $\mathrm{CN}$ or SCN. 
1 Table 3. Summary of SCN half-lives in fish exposed to CN or SCN including relative standard

2 deviation (RSD) and average fish weight. Summary of max concentration of SCN observed in fish

3 exposed to $\mathrm{CN}$ or $\mathrm{SCN}$.

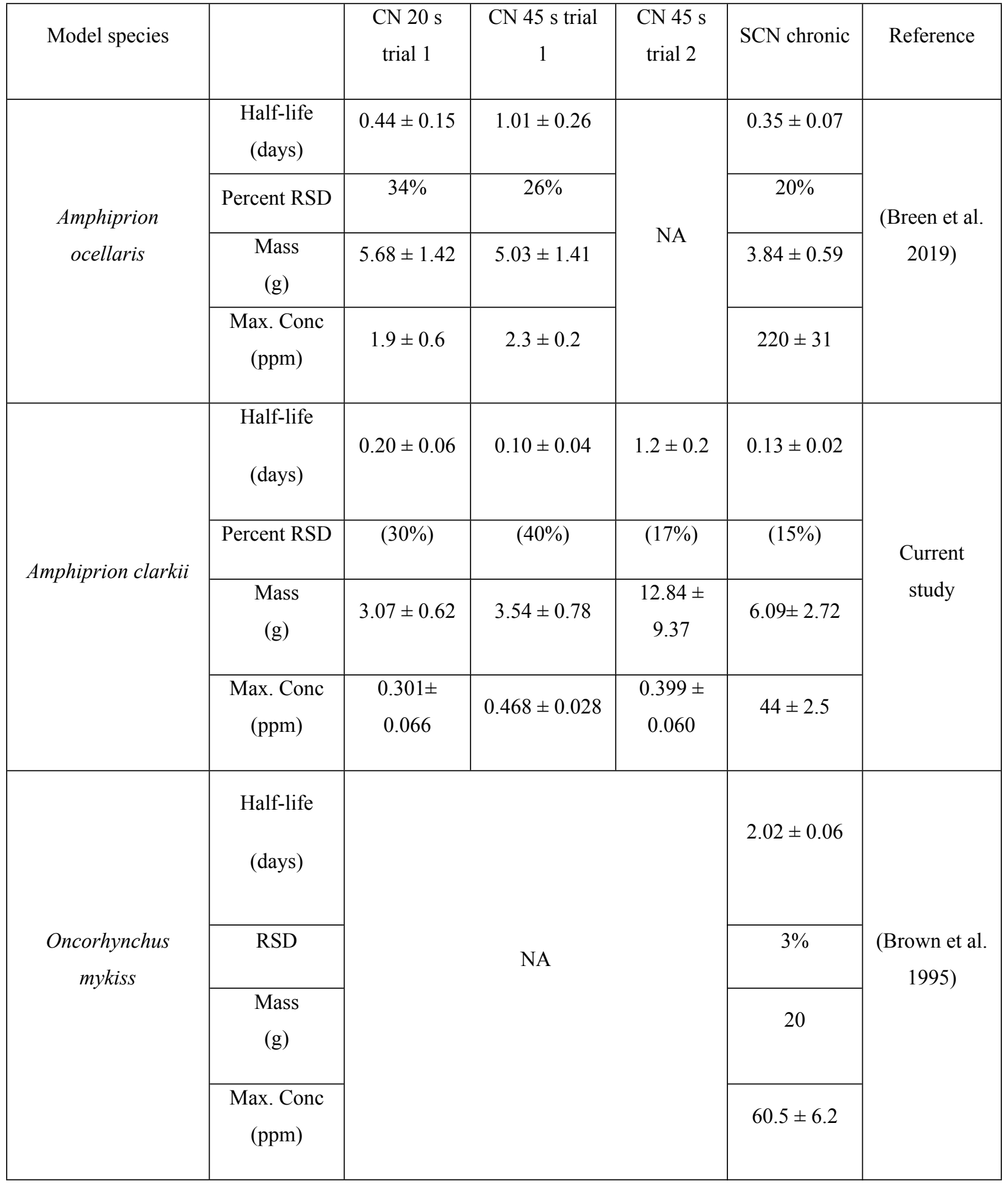

4 